178

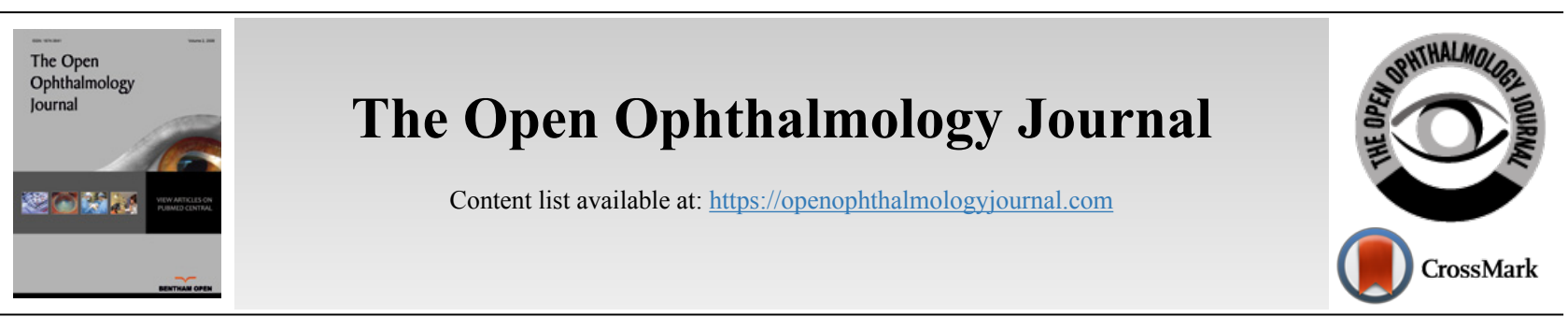

RESEARCH ARTICLE

\title{
Barriers to Low Vision Services Among Optometrists in Saudi Arabia
}

\author{
Ali M. Alsaqr ${ }^{1, *}$ \\ ${ }^{\prime}$ Department of Optometry, College of Applied Medical Sciences, King Saud University, Riyadh, Saudi Arabia
}

\begin{abstract}
:
Introduction:

This study identifies the barriers and challenges to the provision of low vision services among practicing optometrists in Saudi Arabia.

Methods:

In this study, a self-administered online structured survey for practicing optometrists was used. Responses were collected to understand the number and percentage of low vision service providers, level of awareness, and barriers to the provision of low vision services.

Results:

This study included 154 (79 females and 75 males) practicing optometrists. They were from the five regions of Saudi Arabia (23 cities). The age of the practitioners ranged from 22 to 54 years. They had Bachelor's, Master's, and Doctor of Philosophy degrees. Forty-four participants (30\%) provided low vision services. The major barriers reported were lack of training (87\%), lack of awareness about low vision services (76\%), lack of availability of low vision devices $(70 \%)$, lack of motivation $(65 \%)$, low vision services being time-consuming (55\%), being busy in providing general optometry $(65 \%)$, and lack of financial sources $(31 \%)$.

\section{Conclusion:}

Building an efficient model for low vision rehabilitation in Saudi Arabia is needed. Moreover, encouraging more optometrists to be involved in low vision rehabilitation is necessary. There is also a need for more low vision education, national health coverage of patients with low vision, and better collaboration between low vision service providers.
\end{abstract}

Keywords: Optometrist, Eye care, Low vision, Rehabilitation, Visual impairment, Barriers, Constraints.

\begin{tabular}{|l|l|l|r} 
Article History & Received: February 7, 2021 & Revised: June 3, 2021 & Accepted: June 30, 2021
\end{tabular}

\section{INTRODUCTION}

Low vision (LV) or visual impairment is a term used for reduced vision that cannot be fully restored by optical or surgical means. The World Health Organization estimated that 246 million people are visually impaired, and 39 million are blind globally $[1,2]$. In the eastern Mediterranean region, a study has estimated that 4.9 million are blind $(12.5 \%$ of the population), 18.5 million (7.6\%) have LV, and 23.5 million (8.2\%) have a visual impairment [2]. Specifically, in Saudi Arabia (SA), $0.70 \%-6 \%$ of the population are blind, and $7.8 \%-14 \%$ are visually impaired [3 - 9]. Furthermore, correctible visual impairment was reported to be $16 \%-20 \%$ approximately $[10,11]$.

* Address correspondence to this author at the Department of Optometry, College of Applied Medical Sciences, King Saud University, Riyadh, Saudi Arabia; Tel: 00966553497786; Fax: 00966114693536; E-mail: aalsaqr@ksu.edu.sa
Patients with LV retain usable vision; however, they experience some restrictions related to reading and accessing information, mobility, leisure, and daily activities, such as household chores and personal care [12 - 15]. These limitations can decrease general quality of life $[16,17]$, such as loss of independence and increased social isolation and depression [18 - 22]. A multidisciplinary LV rehabilitation program can significantly improve the patients' quality of life [23, 24], thus increasing the average lifespan [25]. The social, personal, and economic cost of vision loss is tremendous [26 - 29].

LV services involve several models; some focus solely on the functional needs of the individual, providing optical and non-optical aids, whereas other models adopt a more comprehensive approach [30]. LV rehabilitation is an emerging branch of medicine involving the efforts of ophthalmologists, optometrists, occupational therapists, physical therapists, social 
workers, LV therapists, vision rehabilitation teachers, and orientation and mobility specialists [31]. In SA, the personnel who provide LV services in traditional hospital-based practices rely heavily on optometrists, with referrals to other specialties as necessary. LV rehabilitation is a relatively new service; for example, in the USA, LV rehabilitation services have been enacted as recently as the past 15 years [32].

Modern LV rehabilitation involves assessment of residual visual functions, prescription of $\mathrm{LV}$ aids, and vision rehabilitation therapy for improving residual skills [31]. In SA, $\mathrm{LV}$ rehabilitation is mainly provided by optometrists, in government/private hospitals, or within educational institutions. Annual financial subsidy for LV aids and other needs is available only to patients who meet certain visual criteria and are registered.

Currently, there is no consistent coverage for $\mathrm{LV}$ rehabilitation, and it is practiced today by relatively few practitioners. Additionally, approximately 250 thousand out of all the Saudi residents older than 40 years have some form of LV (General Authority of Statistics: accessed July 2020) [33]. Nowadays, in SA, public and private clinics provide LV services. University-affiliated teaching faculties also provide various services for patients with LV. The cost of LV aids dispensed to patients is not well defined. Due to vast needs, whether healthcare systems in SA are prepared to deal with these marked challenges is unclear.
For that reason, setting up an efficient and sustainable LV rehabilitation training program is of great necessity. However, to encourage people for such training, an in-depth understanding of the model and barriers of current practices is needed. This study determines the current practice of LV rehabilitation and the barriers faced in providing LV rehabilitation services.

\section{METHODS}

The registrants of the optometrist database of the Saudi Association of Optometry were used to contact the respondents. The responses were collected through an online self-administered structured survey in English. The electronic link of the survey was sent to 380 practicing optometrists with a brief introduction to the study. A follow-up reminder email was sent to them two and four weeks after the link was sent for those who have not responded yet to increase the response rate. The survey was largely based on an instrument that was designed and published previously [34]. The time frame of this study started from June 2020 for approximately two months and was conducted during the COVID-19 pandemic. The details of the questionnaire are given in Appendices (Table 1). The questionnaire contained 30 questions, which included the questions on the participants' demographic details (9 items), knowledge questions (4 items), questions on barriers for the provision of LV services (9 items), and LV rehabilitation practice pattern questions (8 items).

Table 1. Items of the questionnaire.

\begin{tabular}{|c|c|c|}
\hline & Items & Response \\
\hline \multicolumn{3}{|c|}{ Section 1: Respondents Characteristics } \\
\hline 1. & Age & \\
\hline 2. & Gender & Male/female \\
\hline 3. & Qualification & $\mathrm{BSc} / \mathrm{MSc} / \mathrm{PhD} / \mathrm{PG}$ certificate \\
\hline 4. & Organization of Attachment & $\begin{array}{l}\text { Primary care center } \\
\text { Government hospital } \\
\text { Private practice } \\
\text { Others }\end{array}$ \\
\hline 5. & Practice location & Region/ City \\
\hline 6. & Is your Organization a Teaching Hospital? & Yes/ No \\
\hline 7. & Primary areas of your eye care activity & \begin{tabular}{|c} 
General optometrist \\
Community eye health \\
Pediatric services \\
Contact lenses \\
Low vision services Rehabilitation programs
\end{tabular} \\
\hline 8. & No. of years in optometry practice & Years \\
\hline 9. & Practice status & Full/part-time \\
\hline \multicolumn{3}{|c|}{ Section 2: How much do you know about low vision services? } \\
\hline 10. & Have you heard about low vision? & Yes/no \\
\hline 11. & Do you refer patients for low vision care to other centers? & Yes/no/maybe \\
\hline 12. & Do you provide low vision service? & Yes/no \\
\hline 13. & Do you know about the availability of low vision devices? & Yes/no \\
\hline \multicolumn{3}{|c|}{ Section 3: Major barrier/constraint expressed in providing low vision care } \\
\hline 14. & Lack of training/knowledge in low vision care & Yes/no \\
\hline 15. & Lack of awareness about low vision services & Yes/no \\
\hline 16. & Non-availability of low vision devices & Yes/no \\
\hline 17. & Lack of motivation & Yes/no \\
\hline
\end{tabular}




\begin{tabular}{|c|c|c|}
\hline & Items & Response \\
\hline 18. & Low vision care is time-consuming & Yes/no \\
\hline 19. & Busy in providing general optometry services & Yes/no \\
\hline 20. & Ophthalmology services & Yes/no \\
\hline 21. & Low vision care is not lucrative & Yes/no \\
\hline 22. & Low vision services are not effective in helping patients & Yes/no \\
\hline \multicolumn{3}{|c|}{ Section 4: Characteristics of low vision practices (optional for those who do not practice low vision care) } \\
\hline 23. & Do you carry low vision information in your office? & Yes/no \\
\hline 24. & Distance to the nearest low vision clinic & Kilometers \\
\hline 25. & $\begin{array}{l}\text { Do you or someone on your staff talk to patients who have lost vision about how this might limit } \\
\text { their activities? }\end{array}$ & Yes/no \\
\hline 26. & No. of patients per month who have been to low vision rehabilitation & Patients \\
\hline 27. & No. of patients per month referred to low vision services & Patients \\
\hline 28. & In the last year, have you communicated directly with providers at a low vision center? & Yes/no \\
\hline 29. & Are you satisfied with your current low vision services referral practices? & Yes/no \\
\hline 30. & No. of years of low vision practice & Years \\
\hline
\end{tabular}

Statistical Package for the Social Sciences (version 26; IBM Corp., Armonk, NY, USA) was used for all data analyses. The Kruskal-Wallis test was used to understand the differences in awareness, knowledge, and barriers with respect to age, qualification, practice location, and years of experience. $P$ values of $<0.05$ were used to denote statistical significance.

\section{RESULTS}

Among the 380 questionnaires sent, 154 were filled and returned, accounting for a response rate of $40 \%$. The respondents consisted of 79 females $(51.3 \%)$ and 75 males $(48.7 \%)$ and were from the five regions of SA (Central (61\%), Western (15.6\%), Southern (11.7\%), Eastern (7.1\%), and Northern (4.6\%) regions), involving 23 cities. The mean age of the participants was $33.51 \pm 6.79$ years (range, 22-54 years).

The respondents' qualifications and type of organization of attachment are described in Fig. (1) and Table 2, respectively.
Interestingly, only two optometrists who worked in teaching hospitals reported that their primary activity is LV rehabilitation (Table 2). Twenty-two optometrists (14.2\%) reported that they provide LV rehabilitation services routinely along with their usual practice. Most respondents $(88 \%, 136$ respondents) reported that their primary activity is general optometry. The general experience of the respondents is displayed in Fig. (2).

Table 2. The respondents' organization of attachment.

\begin{tabular}{|c|c|}
\hline Organization of Attachment & Number of Participants (\%) \\
\hline Government hospital & $\begin{array}{c}103(67) \\
72(46 \%) \text { of them worked in teaching } \\
\text { hospitals }\end{array}$ \\
\hline Private practice & $31(20)$ \\
\hline Primary care center & $10(6.5)$ \\
\hline Others & $10(6.5)$ \\
\hline
\end{tabular}

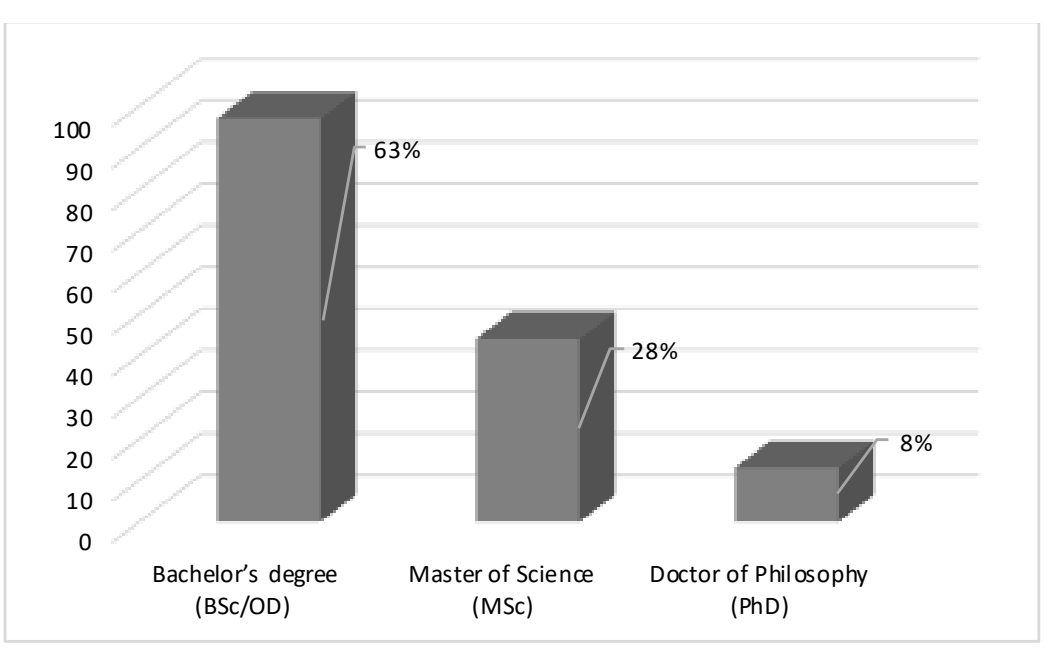

Fig. (1). The distribution of the respondents' qualifications. 


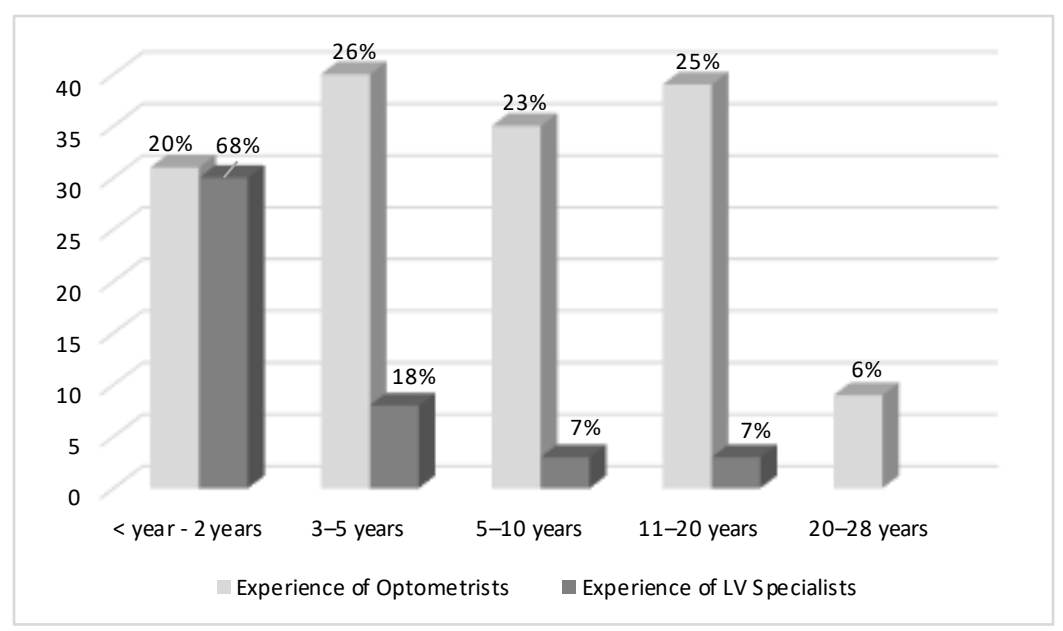

Fig. (2). Illustration of the respondents' expertise in years of the overall group and in the LV specialists group.

The number of respondents who provided LV services was $44(28.5 \%)$. Among the 110 participants who did not provide LV services, 20 stated that they did not refer patients to other LV centers. Approximately half of the respondents (76 participants, 49\%) did not know about the availability of LV devices locally. Moreover, approximately $60 \%$ of the surveyed clinicians (93 respondents) did not provide LV information in their offices. Regarding the major barriers/constraints in providing LV care, their responses are shown in Fig. (3).

In terms of the characteristics of current LV practices, the distance to the nearest LV clinic was within 100 miles in 131 responses, within 200-400 miles in seven responses, within 400-600 miles in six responses, and more than 600 miles up to 1000 miles away in ten responses. Fifty-five respondents (35.5\%) did not educate patients with LV about how this might limit their activities.
The 44 respondents who have LV clinics reported that the monthly number of patients ranged from 1 to 90 . Furthermore, $104(67 \%)$ respondents who did not have LV clinics did not communicate with LV service providers in the past year. Approximately $76 \%$ of the respondents were not satisfied with their current LV service referral practices. Finally, the experience of LV practitioners ranged from less than a year to 20 years (only three clinicians) (Fig. 2).

To understand the effect of the respondents' age, qualification, practice location, and years of experience on the variations of their responses, the Kruskal-Wallis test was performed, which revealed that age impacted the respondents' responses, where older respondents were more likely to provide LV service; 22 of the 44 participants who have LV clinics were in the older group, and they negatively considered that providing LV services is time-consuming (Table 3 ).

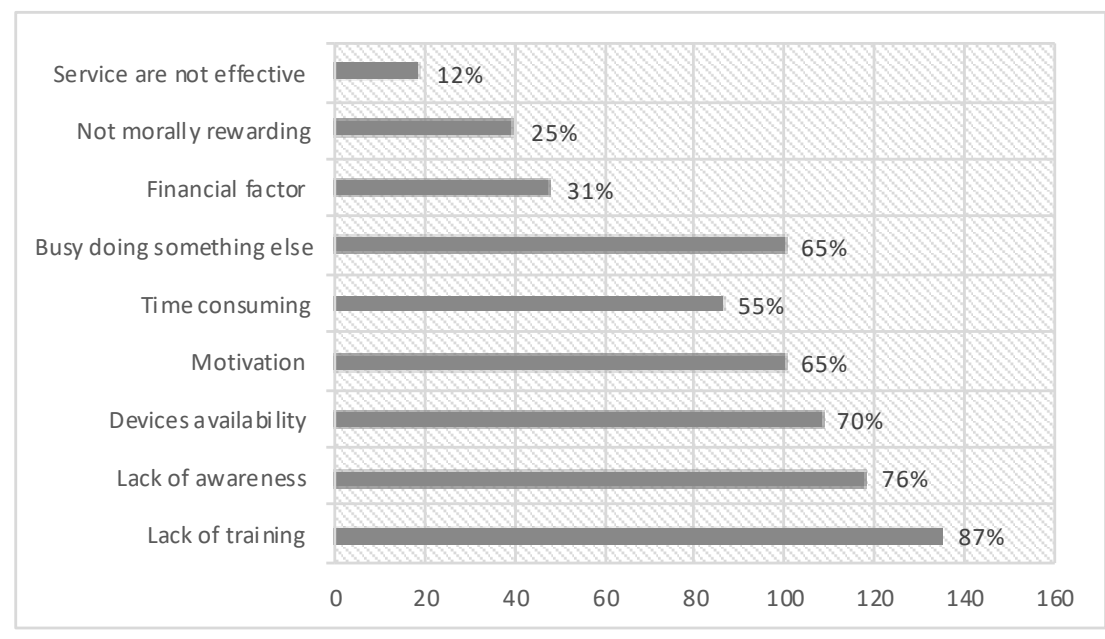

Fig. (3). The reported major barriers/constraints in providing LV care from the respondents' perspective. 
Table 3. The Kruskal-Wallis test investigating the variations in awareness, knowledge, and barriers with respect to age, practice location, and experience.

\begin{tabular}{|c|c|c|c|}
\hline Variable & Age & $\begin{array}{l}\text { Practice } \\
\text { location }\end{array}$ & Experience \\
\hline Providing LV & $\begin{array}{c}H(1)= \\
10.41 ; P= \\
0.001^{*}\end{array}$ & $\begin{array}{c}H(4)=21.3 ; P \\
<0.0001^{*}\end{array}$ & $\begin{array}{c}H(2)=10.8 ; P \\
=0.004 *\end{array}$ \\
\hline Lack of training & NS & $\begin{array}{c}H(4)=14.44 \\
P=0.006^{*}\end{array}$ & NS \\
\hline $\begin{array}{c}\text { Lack of awareness } \\
\text { about LV }\end{array}$ & NS & $\begin{array}{c}H(4)=10.6 ; P \\
=0.03^{*}\end{array}$ & NS \\
\hline $\begin{array}{l}\text { LV care is time- } \\
\text { consuming }\end{array}$ & $\begin{array}{c}H(1)= \\
4.26 \\
P=0.039^{*}\end{array}$ & NS & NS \\
\hline $\mathrm{LV}$ care is not lucrative & NS & $\begin{array}{c}H(4)=18.88 \\
P=0.001^{*}\end{array}$ & NS \\
\hline $\begin{array}{l}\text { LV services are not } \\
\text { effective in helping } \\
\text { patients }\end{array}$ & NS & $\begin{array}{c}H(4)=20.19 \\
P<0.0001^{*}\end{array}$ & $\begin{array}{c}H(2)=9.5 ; P \\
=0.009^{*}\end{array}$ \\
\hline $\begin{array}{c}\text { Carry LV information in } \\
\text { office }\end{array}$ & NS & $\begin{array}{c}H(4)=13.6 ; P \\
=0.008^{*}\end{array}$ & $\begin{array}{c}H(2)=9 ; P= \\
0.01 *\end{array}$ \\
\hline $\begin{array}{c}\text { Talk to patients with LV } \\
\text { about LV activity } \\
\text { limitation }\end{array}$ & NS & $\begin{array}{c}H(4)=13.4 ; P \\
=0.023^{*}\end{array}$ & NS \\
\hline
\end{tabular}

$* P<0.05$ was considered to be statistically significant. LV, low vision; NS, not significant. Age groups: $\mathrm{G} 1=22-37$ years, G2 $=38-55$ years. Practice locations: Central, Eastern, Western, Northern, and Southern regions. Experience: G1= $0-10$ years, $\mathrm{G} 2=11-20$ years, and $\mathrm{G} 3=21-28$ years.

Practice location was another factor affecting the respondents' responses (Table 3). In detail, the number of LV service providers was scarce in the Northern and Southern regions (Central: 24 of 95; Eastern: 3 of 11; Western: 15 of 23; Northern: 1 of 8; and Southern: 1 of 18). The level of lack of training was also different between regions (Central: 86 of 95; Eastern: 8 of 11; Western: 22 of 23; Northern: 4 of 8; and Southern: 15 of 18). Lack of awareness was significantly different between regions; the respondents generally agreed that awareness is crucial to practicing LV (Central: 77 of 95; Eastern: 8 of 11; Western: 19 of 23, Northern: 3 of 8; and Southern: 11 of 18 ). Approximately $70 \%$ of the respondents in the Southern region felt that providing LV services is not financially rewarding; however, only $10 \%$ of the respondents in the Eastern region felt the same way (Central: 28 of 95; Eastern: 1 of 11; Western: 4 of 23; Northern: 2 of 8; and Southern: 13 of 18). The respondents in the Western region believed more than those in other regions that LV services are not effective in helping patients (Central: 7 of 95; Eastern: 1 of 11; Western: 9 of 23; Northern: 2 of 8; and Southern: 1 of 18). The respondents in the Southern region were the poorest in providing information about LV in their offices (Central: 35 of 95; Eastern: 6 of 11; Western: 16 of 23; Northern: 3 of 8; and Southern: 3 of 18). The respondents in the Northern region provided the least education about LV activity limitation (Central: 63 of 95; Eastern: 6 of 11; Western: 17 of 23; Northern: 1 of 8; and Southern: 13 of 18).

In terms of the effect of experience on the respondents' response, the experience did not significantly affect the provision of LV services; however, the availability of information in offices is significantly impacted by this factor.
In detail, experienced clinicians were relatively more involved in providing LV services than startup practitioners (G1: 1-10 years, 12 of 107; G2: 11-20 years, 3 of 39; G3: 21-28 years, 6 of 9). Furthermore, few LV clinicians responded that LV services are not effective (G1: $1-10$ years, 12 of 107; G2: 11-20 years, 3 of 39; G3: 21-28 years, 4 of 9). Finally, most respondents with more than 20 years of experience held information in their offices, whereas approximately $40 \%$ each of the other groups made LV information available in their offices (G1: 1-10 years, 40 of 107; G2: 11-20 years, 15 of 39; G3: $21-28$ years, 8 of 9 ).

\section{DISCUSSION}

This study describes the LV practice patterns of optometrists in SA. The topic was scarcely studied, and this significant gap obscures monitoring and evaluation of providing LV services. These indicators should be known and integrated into more complex health policy strategies for dynamic monitoring and evaluation. The main reason for the anticipated growth in LV rehabilitation worldwide demand is that causes of LV are mainly age-related conditions [35]. In the next two decades, the SA population will become an aging population based on the numbers released by the Saudi Authority of Statistics [33].

This study was conducted using an online survey, which is accessible to design, distribute, and collect responses. However, it has its own set of limitations, including small sample size and poor participation. However, the response rate in this study was $40 \%$, which is more than the response rate in similar studies (response rates ranged from $6.7 \%$ to $36 \%$ ) [36 40]. Furthermore, this study was conducted during the Covid-19 pandemic, but the negative/positive influence of this factor can not be determined as the response rate in previous studies largely varied. Finally, the respondents were from the five main regions of SA, covering 23 cities, which is something we would not accomplish in face-to-face interviews. This study provided insights into the LV practice pattern in SA.

It is more likely that most LV rehabilitation services fall on the shoulder of government hospitals as most respondents are working there. Furthermore, $25 \%$ of the government clinicians who responded to the survey worked in teaching hospitals, all of whom have partly LV clinics; however, only two optometrists stated that providing LV services was their primary activity. This could indicate the importance of teaching facilities in developing the LV rehabilitation model of practice in SA.

Based on the numbers provided by the Saudi General Authority of Statistics, 250 thousand Saudi residents have some form of visual impairment [33]. Therefore, LV rehabilitation is largely needed where ophthalmologists, optometrists, opticians, occupational therapists, rehabilitation teachers, and instructors work together under one roof to provide comprehensive care and service, which is beyond the benefits of optical aid, a cane, or large-print materials could provide.

Unfortunately, only 44 practicing optometrists are involved in providing LV rehabilitation services. This result matches with the approximate numbers in other countries, as only a few countries have more than ten LV rehabilitation service 
providers per 10 million of their population [41]. However, inequitable distribution and a significant shortfall exist in the current LV practitioners in comparison with demands. Increasing the number of LV service providers and their distributions are of crucial necessity.

Among the challenges to the effective practice of providing LV rehabilitation services, the lack of effective referral systems to have a continuity of care is the biggest concern [35]. In this study, the availability of LV services and referral systems was a major issue. Specifically, only $50 \%$ of the respondents referred patients to LV clinics, and 50\% actually knew about the availability of LV devices locally. These challenges should be overcome through advocating LV services among professionals, and health institutions should also adopt referral systems that serve the best interest of patients with LV.

In terms of understanding the barriers for practitioners in providing LV services, the major barriers covered a wide range of subjects, including training shortage, availability of LV devices, and professional motivation to providing LV services. Both King Saud University and Qassim University are currently offering undergraduate degrees in optometry which involve LV rehabilitation training. However, students choose which branch of optometry would be their subspecialty. Nongovernmental organizations such as the Saudi Association of Optometry, the Saudi Ophthalmological Society, and the EBSAR Foundation funded and organized short LV rehabilitation training workshops; however, these efforts were not sustained. This may explain the poor uptake of optometrists on LV services, and although a considerable number of practitioners were trained, only a few still continue the practice. This study advocates that training programs established by governmental and non-governmental facilities should be expanded in capacity through postgraduate certificates accredited by the Saudi Commission for Health Specialties, and human resources should be improved in the absence of sustainable training programs by tackling the barriers and challenges and renewing interest in the field of LV care through quality training and improved LV service delivery.

Increasing the awareness of the challenges patients with LV face and the development of the field of LV rehabilitation are another front that should be tackled through professional, governmental, and non-governmental efforts. The respondents emphasized the importance of the availability of LV devices across the country. It could be of importance that patients receive LV aids on loan or free of charge when examined within a government-run rehabilitation center. Easing the accessibility to LV aids is necessary not only for the privileged patients but also for the underprivileged patients. Motivating LV practitioners is another challenge that could involve financial, moral, and professional motivation and giving the LV specialists the time and space to provide such complex services. A few clinicians reported that LV services are not that effective in helping patients. This can be tackled through professional seminars, case studies, and articles addressing the effectiveness of LV rehabilitation [30, 42 - 45].

Patients with LV face social and economic challenges, which tend to delay uptake of LV services [41]. Social challenges could involve access to transportation. Specifically, the geographic distribution of LV rehabilitation services is another challenge in developing countries [46]. In this study, the distribution of LV centers was diverse, where some clinics were within 100 miles, but some were as far as 1,000 miles. The shortage of LV centers seems to be in peripheral areas; therefore, more even distribution with considerable accessibility greatly needs to be addressed by the health policymakers. It has also been suggested that telerehabilitation had positive feedback from both the participants and providers [47]. Hence, telerehabilitation for patients with LV can be deployed in peripheral areas.

Although $70 \%$ of the respondents reported that they would inform patients about LV activity limitations, educating patients with LV about the activity limitations and discussing with them, their rehabilitation options are the main barriers to accessing LV services from the patients' perspective, as reported previously [48 - 50]. Patient education and training should be incorporated more in routine optometric practice.

Understanding patient's perspectives about barriers to LV rehabilitation service access would improve the quality of the service. Studies have suggested that the barriers included lack of awareness on referral criteria, availability of LV clinics, misconceptions on LV services, miscommunication by eye care professionals, clinic location and transportation, the need to feel independent, negative societal views about LV services, discouragement from family and friends, cost of LV aids, and reduced perception of vision loss in relation to other losses in life [48 - 50]. Patients' enablers included structured referral criteria and referral pathways to LV clinics and patient opportunities to be aware of LV services [49, 51]. These barriers and enablers should be tackled at all levels, including health institutions, non-governmental support groups, and all health professionals related to the LV field.

The referral system and the number of patients accommodated in LV clinics seem to be essential variables among the respondents. A more structured referral system, more space, and more time shall be provided for a more effective service. A similar study has suggested that there must be enough trained LV personnel, proper testing equipment, and proper LV aids made available with subsidy or free of charge [52]. However, these capabilities in most developing countries are not available due to the lack of interest in the subject due to few training centers [41].

LV rehabilitation is needed for an aging population [36]. Some of the aforementioned barriers are unmanageable for the optometrists themselves, such as more education, nearby LV center/clinic, and funding for LV devices. These barriers have also been previously reported in Australia [53]. Another study suggested that patients' ability to afford access to optometric LV services and LV devices is a cause for concern [54]. Therefore, reimbursement for LV services should compensate for the chair time, staff training, and the associated administrative work [36].

Age, practice location, and years of experience were causes of variations in the respondents' responses. It seems that as clinicians get more experienced, they build a positive attitude toward LV services and get more involved in providing LV services. In addition, as clinicians get more experienced, they tend to make LV information available in their offices, which could be due to the increasing number of patients they examine through the years and the challenges described to them by patients with LV. Although there was a significant variation in 
the respondents' responses regarding "LV services are not effective" due to experience, only a relatively small number of clinicians believed that LV services are not effective and can be tackled, as discussed earlier.

The practice location was a source of the variations in the respondents' responses. Only two LV clinics were available in the Northern and Southern regions, emphasizing the urgency and importance of developing LV rehabilitation service in those areas. Furthermore, lack of training and financial incentive was a major barrier to providing LV services in the Northern and Southern regions. Clinicians from the Southern region were the least in carrying LV information in their practices, and those from the Northern region were the least in providing education to patients about LV activity limitations. Therefore, overcoming these challenges is of priority for those interested in developing LV rehabilitation centers in those areas.

\section{CONCLUSION}

In conclusion, building an efficient model for $\mathrm{LV}$ rehabilitation in SA is needed. To encourage more optometrists to be involved in LV rehabilitation, more LV education, national health coverage for patients with $\mathrm{LV}$, and better collaboration between LV providers are necessary.

\section{LIST OF ABBREVIATIONS}

$\begin{array}{lll}\mathbf{L V} & = & \text { Low Vision } \\ \text { SA } & = & \text { Saudi Arabia }\end{array}$

\section{ETHICS APPROVAL AND CONSENT TO PARTICIPATE}

This study was approved by the institutional ethical committee of King Saud University, Saudi Arabia under approval no. \#CAMS067-3839.

\section{HUMAN AND ANIMAL RIGHTS}

No animals were used in this research. All human research procedures followed were in accordance with the ethical standards of the committee responsible for human experimentation (institutional and national), and with the Helsinki Declaration of 1975, as revised in 2013.

\section{CONSENT FOR PUBLICATION}

All patients participated on a voluntary basis and gave their informed consent.

\section{AVAILABILITY OF DATA AND MATERIALS}

The data presented in this study are available on reasonable request from the corresponding author [A.A].

\section{FUNDING}

This research was funded by the College of Applied Medical Sciences Research Centre and the Deanship of Scientific Research at King Saud University.

\section{CONFLICT OF INTEREST}

The author declares no conflict of interest, financial or otherwise.

\section{ACKNOWLEDGEMENTS}

The authors extend their appreciation to the College of Applied Medical Sciences Research Centre and the Deanship of Scientific Research at King Saud University for funding this research. The authors also thank the RSSU at King Saud University for technical support.

\section{REFERENCES}

[1] World Health Organization. Visual impairment and blindness. 2014.

[2] Pascolini D, Mariotti SP. Global estimates of visual impairment: 2010 Br J Ophthalmol 2012; 96(5): 614-8. [http://dx.doi.org/10.1136/bjophthalmol-2011-300539] [PMID: 22133988]

[3] Al-Shaaln FF, Bakrman MA, Ibrahim AM, Aljoudi AS. Prevalence and causes of visual impairment among Saudi adults attending primary health care centers in northern Saudi Arabia. Ann Saudi Med 2011; 31(5): 473-80.

[http://dx.doi.org/10.4103/0256-4947.84624] [PMID: 21911984]

[4] Tabbara KF, Ross-Degnan D. Blindness in Saudi Arabia. JAMA 1986; 255(24): 3378-84

[http://dx.doi.org/10.1001/jama.1986.03370240048035] [PMID: 3712697]

[5] al Faran MF, Ibechukwu BI. Causes of low vision and blindness in south western Saudi Arabia. A hospital-based study. Int Ophthalmol 1993; 17(5): 243-7.

[http://dx.doi.org/10.1007/BF01007790] [PMID: 8132401]

[6] Alghamdi HF. Causes of irreversible unilateral or bilateral blindness in the Al Baha region of the Kingdom of Saudi Arabia. Saudi J Ophthalmol 2016; 30(3): 189-93.

[http://dx.doi.org/10.1016/j.sjopt.2016.06.001] [PMID: 28210181]

[7] Al-Ghamdi AS. Adults visual impairment and blindness - An overview of prevalence and causes in Saudi Arabia. Saudi J Ophthalmol 2019; 33(4): 374-81.

[http://dx.doi.org/10.1016/j.sjopt.2019.10.001] [PMID: 31920448]

[8] Hajar S, Al Hazmi A, Wasli M, Mousa A, Rabiu M. Prevalence and causes of blindness and diabetic retinopathy in Southern Saudi Arabia. Saudi Med J 2015; 36(4): 449-55.

[http://dx.doi.org/10.15537/smj.2015.4.10371] [PMID: 25828282]

[9] Al Ghamdi AH, Rabiu M, Hajar S, Yorston D, Kuper H, Polack S. Rapid assessment of avoidable blindness and diabetic retinopathy in Taif, Saudi Arabia. Br J Ophthalmol 2012; 96(9): 1168-72. [http://dx.doi.org/10.1136/bjophthalmol-2012-301874]

[PMID: 22790436

[10] Aldebasi YH. Prevalence of correctable visual impairment in primary school children in Qassim Province, Saudi Arabia. J Optom 2014; 7(3): 168-76.

[http://dx.doi.org/10.1016/j.optom.2014.02.001] [PMID: 25000873]

[11] Alsaqr A, Abu Sharha A, Fagehi R, et al. The visual status of adolescents in Riyadh, Saudi Arabia: A population study. Clin Ophthalmol 2018; 12: 965-72.

[http://dx.doi.org/10.2147/OPTH.S162319] [PMID: 29872255]

[12] Weih LM, Hassell JB, Keeffe J. Assessment of the impact of vision impairment. Invest Ophthalmol Vis Sci 2002; 43(4): 927-35. [PMID: 11923230]

[13] Lamoureux EL, Hassell JB, Keeffe JE. The determinants of participation in activities of daily living in people with impaired vision. Am J Ophthalmol 2004; 137(2): 265-70.

[http://dx.doi.org/10.1016/j.ajo.2003.08.003] [PMID: 14962415]

[14] Heyl V, Wahl H-W. Psychosocial adaptation to age-related vision loss: A six-year perspective. J Vis Impair Blind 2001; 95: 739-48. [http://dx.doi.org/10.1177/0145482X0109501204]

[15] West SK, Munoz B, Rubin GS, et al. Function and visual impairment in a population-based study of older adults. The SEE project. Salisbury Eye Evaluation. Invest Ophthalmol Vis Sci 1997; 38(1): 72-82. [PMID: 9008632]

[16] Habib F, Irshad E. Impact of visual impairment on quality of life among adolescents. FWU J Soc Sci 2018; 12: 149-55.

[17] Langelaan M, de Boer MR, van Nispen RM, Wouters B, Moll AC, van Rens GH. Impact of visual impairment on quality of life: A comparison with quality of life in the general population and with other chronic conditions. Ophthalmic Epidemiol 2007; 14(3): 119-26. [http://dx.doi.org/10.1080/09286580601139212] [PMID: 17613846]

[18] Burmedi D, Becker S, Heyl V, Wahl H-W, Himmelsbach I. Emotional and social consequences of age-related low vision. Vis Impair Res 
2002; 4: 47-71.

[http://dx.doi.org/10.1076/vimr.4.1.47.15634]

[19] Rovner BW, Ganguli M. Depression and disability associated with impaired vision: The MoVies Project. J Am Geriatr Soc 1998; 46(5): $617-9$.

[http://dx.doi.org/10.1111/j.1532-5415.1998.tb01080.x] [PMID: 9588377]

[20] Alma MA, Van der Mei SF, Groothoff JW, Suurmeijer TP. Determinants of social participation of visually impaired older adults. Qual Life Res 2012; 21(1): 87-97.

[http://dx.doi.org/10.1007/s11136-011-9931-6] [PMID: 21633880]

[21] Alma MA, van der Mei SF, Melis-Dankers BJM, van Tilburg TG, Groothoff JW, Suurmeijer TP. Participation of the elderly after vision loss. Disabil Rehabil 2011; 33(1): 63-72.

[http://dx.doi.org/10.3109/09638288.2010.488711] [PMID: 20518624]

[22] Brunes A, B Hansen M, Heir T. Loneliness among adults with visual impairment: Prevalence, associated factors, and relationship to life satisfaction. Health Qual Life Outcomes 2019; 17(1): 24.

[http://dx.doi.org/10.1186/s12955-019-1096-y] [PMID: 30709406]

[23] Lamoureux EL, Pallant JF, Pesudovs K, Rees G, Hassell JB, Keeffe JE. The effectiveness of low-vision rehabilitation on participation in daily living and quality of life. Invest Ophthalmol Vis Sci 2007; 48(4): 1476-82.

[http://dx.doi.org/10.1167/iovs.06-0610] [PMID: 17389474]

[24] Hinds A, Sinclair A, Park J, Suttie A, Paterson H, Macdonald M. Impact of an interdisciplinary low vision service on the quality of life of low vision patients. Br J Ophthalmol 2003; 87(11): 1391-6. [http://dx.doi.org/10.1136/bjo.87.11.1391] [PMID: 14609841]

[25] Culham LE, Ryan B, Jackson AJ, et al. Low vision services for vision rehabilitation in the United Kingdom. Br J Ophthalmol 2002; 86(7): 743-7.

[http://dx.doi.org/10.1136/bjo.86.7.743] [PMID: 12084742]

[26] Gordon KD, Cruess AF, Gordois A, Cutler H, Pezzullo L, Winyard S, et al. The global cost of vision loss. Invest Ophthalmol Vis Sci 2011; 52: 5543 .

[27] Cruess AF, Gordon KD, Bellan L, Mitchell S, Pezzullo ML. The cost of vision loss in Canada. 2. Results. Can J Ophthalmol 2011; 46(4): 315-8.

[http://dx.doi.org/10.1016/j.jcjo.2011.06.006] [PMID: 21816249]

[28] Taylor HR, Pezzullo ML, Keeffe JE. The economic impact and cost of visual impairment in Australia. Br J Ophthalmol 2006; 90(3): 272-5. [http://dx.doi.org/10.1136/bjo.2005.080986] [PMID: 16488942]

[29] Wittenborn JS, Zhang X, Feagan CW, et al. The economic burden of vision loss and eye disorders among the United States population younger than 40 years. Ophthalmology 2013; 120(9): 1728-35. [http://dx.doi.org/10.1016/j.ophtha.2013.01.068] [PMID: 23631946]

[30] Binns AM, Bunce C, Dickinson C, et al. How effective is low vision service provision? A systematic review. Surv Ophthalmol 2012; 57(1): 34-65.

[http://dx.doi.org/10.1016/j.survophthal.2011.06.006] [PMID: 22018676]

[31] Markowitz SN. Principles of modern low vision rehabilitation. Can J Ophthalmol 2006; 41(3): 289-312.

[http://dx.doi.org/10.1139/I06-027] [PMID: 16767184]

[32] Stelmack J. Emergence of a rehabilitation medicine model for low vision service delivery, policy, and funding. Optometry 2005; 76(5): 318-26.

[http://dx.doi.org/10.1016/S1529-1839(05)70315-8] [PMID: 15884422]

[33] Saudi Authority of Statistics. 2021. Available From: https://www. stats.gov.sa/en

[34] Khan SA, Shamanna B, Nuthethi R. Perceived barriers to the provision of low vision services among ophthalmologists in India. Indian $\mathrm{J}$ Ophthalmol 2005; 53(1): 69-75.

[http://dx.doi.org/10.4103/0301-4738.15293] [PMID: 15829755]

[35] Chiang PP, Marella M, Ormsby G, Keeffe J. Critical issues in implementing low vision care in the Asia-Pacific region. Indian J Ophthalmol 2012; 60(5): 456-9.

[http://dx.doi.org/10.4103/0301-4738.100549] [PMID: 22944759]

[36] Lam N, Leat SJ, Leung A. Low-vision service provision by optometrists: A Canadian nationwide survey. Optom Vis Sci 2015; 92(3): 365-74

[http://dx.doi.org/10.1097/OPX.0000000000000512] [PMID: 25599339]

[37] Kammer R, Sell C, Jamara RJ, Kollbaum E. Survey of optometric low vision rehabilitation training methods for the moderately visually impaired. Optometry 2009; 80(4): 185-92. [http://dx.doi.org/10.1016/j.optm.2008.10.015] [PMID: 19329062]

[38] Keeffe JE, Lovie-Kitchin JE, Taylor HR. Referral to low vision services by ophthalmologists. Aust N Z J Ophthalmol 1996; 24(3): 207-14.

[http://dx.doi.org/10.1111/j.1442-9071.1996.tb01582.x] [PMID: 8913122]

[39] Lovie-Kitchin JE, Keeffe JE, Taylor HR. Referral to low vision services by optometrists. Clin Exp Optom 1996; 79: 227-34.

[40] Lim HY, O'Connor PM, Keeffe JE. Low vision services provided by optometrists in Victoria, Australia. Clin Exp Optom 2008; 91(2): 177-82.

[http://dx.doi.org/10.1111/j.1444-0938.2007.00214.x]

[PMID: 18271781]

[41] Chiang PPC, O'Connor PM, Le Mesurier RT, Keeffe JE. A global survey of low vision service provision. Ophthalmic Epidemiol 2011; 18(3): 109-21.

[http://dx.doi.org/10.3109/09286586.2011.560745] [PMID: 21609239]

[42] Leat SJ, Fryer A, Rumney NJ. Outcome of low vision aid provision: The effectiveness of a low vision clinic. Optom Vis Sci 1994; 71(3): 199-206.

[http://dx.doi.org/10.1097/00006324-199403000-00009] [PMID: 8196946]

[43] Raasch TW, Leat SJ, Kleinstein RN, Bullimore MA, Cutter GR. Evaluating the value of low-vision services. J Am Optom Assoc 1997; 68(5): $287-95$.

[PMID: 9170794]

[44] Court H, Ryan B, Bunce C, Margrain TH. How effective is the new community-based Welsh low vision service? Br J Ophthalmol 2011; 95(2): 178-84.

[http://dx.doi.org/10.1136/bjo.2010.179606] [PMID: 20601662]

[45] de Boer MR, Twisk J, Moll AC, Völker-Dieben HJ, de Vet HC, van Rens GH. Outcomes of low-vision services using optometric and multidisciplinary approaches: A non-randomized comparison. Ophthalmic Physiol Opt 2006; 26(6): 535-44.

[http://dx.doi.org/10.1111/j.1475-1313.2006.00424.x] [PMID: 17040417]

[46] Chiang PP, Xie J, Keeffe JE. Identifying the critical success factors in the coverage of low vision services using the classification analysis and regression tree methodology. Invest Ophthalmol Vis Sci 2011; 52(5): $2790-5$.

[http://dx.doi.org/10.1167/iovs.10-5460] [PMID: 20926823]

[47] Bittner AK, Yoshinaga P, Bowers A, Shepherd JD, Succar T, Ross NC. Feasibility of telerehabilitation for low vision: satisfaction ratings by providers and patients. Optom Vis Sci 2018; 95(9): 865-72.

[http://dx.doi.org/10.1097/OPX.0000000000001260] [PMID: 30169361]

[48] Lam N, Leat SJ. Barriers to accessing low-vision care: the patient's perspective. Can J Ophthalmol 2013; 48(6): 458-62.

[http://dx.doi.org/10.1016/j.jcjo.2013.02.014] [PMID: 24314403]

[49] Sarika G, Venugopal D, Sailaja MVS, Evangeline S, Krishna Kumar R. Barriers and enablers to low vision care services in a tertiary eye care hospital: A mixed method study. Indian J Ophthalmol 2019; 67(4): 536-40.

[http://dx.doi.org/10.4103/ijo.IJO_1215_18] [PMID: 30900589]

[50] Pollard TL, Simpson JA, Lamoureux EL, Keeffe JE. Barriers to accessing low vision services. Ophthalmic Physiol Opt 2003; 23(4): $321-7$.

[http://dx.doi.org/10.1046/j.1475-1313.2003.00123.x] [PMID: 12828622]

[51] Matti AI, Pesudovs K, Daly A, Brown M, Chen CS. Access to lowvision rehabilitation services: Barriers and enablers. Clin Exp Optom 2011; 94(2): 181-6.

[http://dx.doi.org/10.1111/j.1444-0938.2010.00556.x] [PMID: 21175824]

[52] Dandona R, Dandona L, Srinivas M, Giridhar P, Nutheti R, Rao GN. Planning low vision services in India: A population-based perspective. Ophthalmology 2002; 109(10): 1871-8.

[http://dx.doi.org/10.1016/S0161-6420(02)01183-1]

12359608]

[53] Bentley SA, Jackson AJ, Johnston AW, et al. Advancing low vision services: A plan for Australian optometry. Clin Exp Optom 2014; 97(3): 214-20.

[http://dx.doi.org/10.1111/cxo.12139] [PMID: 24766509]

[54] Gold D, Simson H. Identifying the needs of people in Canada who are blind or visually impaired: Preliminary results of a nation-wide study. Int Congr Ser 2005; 1282: 139-42.

[http://dx.doi.org/10.1016/j.ics.2005.05.055] 